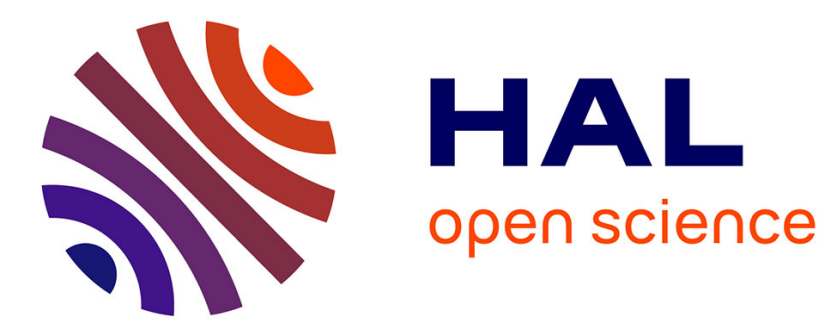

\title{
Plasma antioxidant status in septic critically ill patients: a decrease over time
}

\author{
Jean-Marc Doise, Ludwig Serge Aho, Jean-Pierre Quenot, Jean-Claude \\ Guilland, Marianne Zeller, Catherine Vergely, Herve Aube, Bernard Blettery, \\ Luc Rochette
}

\section{To cite this version:}

Jean-Marc Doise, Ludwig Serge Aho, Jean-Pierre Quenot, Jean-Claude Guilland, Marianne Zeller, et al.. Plasma antioxidant status in septic critically ill patients: a decrease over time. Fundamental \& Clinical Pharmacology, 2008, 22 (2), pp.203 - 209. 10.1111/j.1472-8206.2008.00573.x . hal-03437197

\section{HAL Id: hal-03437197 \\ https://u-bourgogne.hal.science/hal-03437197}

Submitted on 19 Nov 2021

HAL is a multi-disciplinary open access archive for the deposit and dissemination of scientific research documents, whether they are published or not. The documents may come from teaching and research institutions in France or abroad, or from public or private research centers.
L'archive ouverte pluridisciplinaire HAL, est destinée au dépôt et à la diffusion de documents scientifiques de niveau recherche, publiés ou non, émanant des établissements d'enseignement et de recherche français ou étrangers, des laboratoires publics ou privés. 


\title{
PLASMA ANTIOXIDANT STATUS IN SEPTIC CRITICALLY ILL
}

\section{PATIENTS: A DECREASE OVER TIME.}

\author{
JEAN-MARC DOISE ${ }^{1}$, LUDWIG SERGE AHO ${ }^{2}$, JEAN-PIERRE QUENOT ${ }^{1}$, \\ JEAN-CLAUDE GUILLAND ${ }^{3}$, MARIANNE ZELLER ${ }^{3}$, CATHERINE \\ VERGELY $^{3}$, HERVE AUBE $^{1}$, BERNARD BLETTERY $^{1}$, LUC ROCHETTE $^{3}$ \\ ${ }^{1}$ Service de Réanimation Médicale, ${ }^{2}$ Service d'Epidémiologie et Hygiène \\ Hospitalières, \\ ${ }^{3}$ Laboratoire de Physiopathologie et Pharmacologie Cardiovasculaires \\ Expérimentales, CHU - Facultés de Médecine et de Pharmacie - IFR N 100 - \\ DIJON - FRANCE
}

Running head: Plasma antioxidant status in septic patients

Corresponding author : Pr Luc ROCHETTE

LABORATOIRE DE PHYSIOPATHOLOGIE ET PHARMACOLOGIE CARDIOVASCULAIRES EXPERIMENTALES

7 Bd Jeanne d'Arc, BP 87900, 21079 DIJON Cedex

Tel : 03.80.39.32.91, Fax : 03.80.39.32.93

E-mail : rochette@u-bourgogne.fr

Financial supports: Supported with funding from the Centre Hospitalier Universitaire de Dijon, France; Region Bourgogne. 


\section{Abstract:}

Severe septic states in humans are responsible for intense intravascular oxidative stress. We determined changes in total plasma antioxidant capacity (TAC) and plasma antioxidant concentrations (PAC) in 56 septic patients, separated in degrees of severity (septic shock $n=37$, severe sepsis $n=19$ ) and 6 healthy volunteers.

At the onset of illness, there was no difference in the TAC values between the three groups (healthy subjects $2.18 \pm 0.04$; septic shock $2.09 \pm 0.09$; severe sepsis $2.03 \pm 0.07)$. However, over a ten-day follow-up, a similar time-decline of TAC was observed in the two septic populations, while a sharp and persistent decrease in vitamin $\mathrm{C}$ concentrations was underlined. TAC was statistically linked to uric acid, proteins, albumin and bilirubin, but not with any vitamin (A, C or E).

TAC, unable to distinguish severe sepsis and septic shock, is unlikely to be a particularly useful outcome measure.

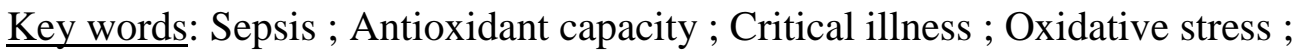

Vitamin C ; Vitamin E.

\section{Abbreviations:}

APC: Allophycocyanin

DHA: Dehydroascorbate

ICU: Intensive Care Unit

ORAC: Oxygen Radical Absorbing Capacity 
ROS: Reactive Oxygen Species

SAPS: Simplified Acute Physiology Score

SOFA: Sepsis-related Organ Failure Assessment

TAC: total Antioxidant Capacity 


\section{INTRODUCTION}

Despite recent improvements in intensive care monitoring, diagnostic tools and therapies, sepsis remains a continuing challenge and a major problem facing critical care practitioners. Severe infections are leading causes of morbidity and mortality in Intensive Care Units (ICU) [1, 2].The pathophysiology of these septic states is complex, involving many mediators and leading to the activation of the inflammatory cascade. However, there is available data which underlines the role of reactive oxygen species (ROS) as fundamental, though not the unique, mediators in this pathogenesis [3-5].

In the last few years, the imbalance between pro-inflammatory and antiinflammatory response in maintaining homeostasis in critical ill patients has come to the fore-front. The inflammatory response to acute infection involves the activation of various cells such as leukocytes and other inflammatory cells, leading to a massive production of ROS. These radicals have toxic effects, including lipid oxidation, protein and DNA damage. Basic research is continually discovering new roles played by the excessive production of ROS in the different aspects of cardiovascular disease, including impaired vasomotor reactivity, which is a key in the pathophysiology of sepsis. However, recent evidence has demonstrated that ROS are produced in a controlled fashion, and are likely to have critical signalling and growth promoting functions [6].

Antioxidant defences play a crucial role in modulating the ambient steady-state levels of ROS. The fundamental defences of the body against ROS include scavenger enzymes (superoxide dismutase, catalase, glutathione peroxidase) and 
lipid and water soluble endogenous antioxidant compounds of metabolic or nutritional origins. For example, bilirubin, uric acid, proteins and antioxidant vitamins are able to scavenge circulating oxidants. Vitamin $\mathrm{C}$ and $\mathrm{E}$ constitute the first line of defence against intravascular oxidants involved in sepsis. These vitamins have been described as exerting multiple beneficial effects in cardiovascular disorders and they improve endothelium-dependent vasodilatation $[7,8]$. Because of the many different antioxidant components in serum, the relative difficulty of measuring each antioxidant separately and the greater protection provided by the combined effect of the different antioxidants compared to that of any compound alone, simple methods to measure total antioxidant capacity (TAC) have been developed [9]. Cao et al have provided a sensitive and reliable tool to quantify the cumulative action of all the antioxidants present in plasma and other biological fluids [10]. The capacity of known and unknown antioxidants and their synergistic interactions are therefore assessed.

Different studies have attempted to describe the evolution of TAC in septic patients, nevertheless, their conclusions were contradictory and the clinical significance of this tool, in septic conditions, has yet to be determined [11, 12]. Therefore, in the present study, we have investigated the time-sequence changes of TAC in two groups of patients each with a degree of infection severity: severe sepsis and septic shock. The evolution in the main plasma antioxidant components and their correlation with TAC were evaluated. 


\section{MATERIALS AND METHODS}

\section{Subjects}

Between February 2000 and February 2001, patients with acute infection were consecutively enrolled in our intensive care unit (ICU). Their recruitment was within $18 \mathrm{~h}$ of the onset of their septic symptoms. Criteria defined by the American College of Chest Physicians/Society of Critical Care Medicine consensus group were used to categorise the patients: patients were included into severe sepsis group or sepsis shock group if they fulfilled the defined criteria during the 10-day follow-up [1]. Subjects with severe sepsis at the onset who developed septic shock were included into the septic shock group. Six healthy volunteers, free of major or inflammatory disease, and not following any treatment, donated blood to provide reference values for this study.

At the time of enrolment, clinical data were recorded (age, gender, diagnosis). The Simplified Acute Physiology Score (SAPS II) was calculated within 24 hours of admission, the Sepsis-related Organ Failure Assessment (SOFA) score was noted daily [13].

The included patients were continuously monitored till their discharge from the ICU and they were treated according to the standard therapeutic policy of our unit, no antioxidant treatment was administered to the patients and all patients were fed with enteral nutrition, which represent the unique source of vitamin $\mathrm{A}, \mathrm{C}$ and $\mathrm{E}$. The survival status was defined according to whether the patient survived beyond the $28^{\text {th }}$ day. 
This study was approved by the local clinical research committee, and informed consent was obtained from both healthy volunteers and patients or their next of kin.

\section{Sample preparation}

A blood sample, from each septic patient, was collected daily, from day 1 to day 10 , or until the ICU patient's discharge or death. For the healthy volunteers, only one sample was taken. For the plasma antioxidant capacity and vitamin measurements, each sample was immediately centrifuged, divided into aliquot portions and stored at $-80^{\circ} \mathrm{C}$ until assayed.

\section{Plasma total antioxidant capacity}

The method employed was that described by Cao et al [10]. This technique is based on the ability of plasma components to protect an indicator protein, allophycocyanin (APC), whose fluorescence is altered when it is oxidised. Oxidative stress is induced in vitro by a peroxyl radical generator, 2,2' -azobis(2amidinopropane) dihydrochloride (AAPH). Results are expressed by measuring the net protection offered by plasma (dilution 1/1000), compared to a reference antioxidant (6-hydroxy-2,5,7,8-tetramethylchroman-2-carboxylic acid or trolox, 1 $\mu \mathrm{M}$, a water soluble vitamin $\mathrm{E}$ analogue). APC fluorescence was measured at $37^{\circ} \mathrm{C}$ and at $652 \mathrm{~nm}$, after excitation at $598 \mathrm{~nm}$, every minute until the end of the oxidation reaction. Results were expressed in ORAC (oxygen radical absorbing 
capacity) units, where 1 ORAC unit represents the net protection provided by 1 $\mu \mathrm{M}$ trolox.

For each sample, the TAC evaluation was duplicated and averaged. For the same patient, all the samples were assayed on the same day; storage duration at $-80^{\circ} \mathrm{C}$ was less than a month.

\section{Antioxidant levels}

Concentration of vitamin A (retinol), vitamin $\mathrm{C}$ (ascorbic acid) and vitamin $\mathrm{E}(\alpha-$ tocopherol) were determined by high-performance liquid chromatography. For accurate assessment of serum $\alpha$-tocopherol, the results were expressed in term of a lipid ratio: $\alpha$-tocopherol was divided by the sum of cholesterol and triglycerides ( unit $=$ mg per $\mathrm{g}$ of serum lipids). Proteins, albumin, total bilirubin, serum lipids (cholesterol and triglycerides) and uric acid were measured by commercial analysing kits on an automated biochemical analyser (Radiometer ${ }^{\circledR}$ ALB 725) according to the manufacturer's instructions.

\section{Chemicals and instruments}

Trolox (6-hydroxy-2,5,7,8-tetramethylchroman-2-carboxylic acid) was obtained from Aldrich ${ }^{\circledR}$. 2,2'-azo-bis (2-aminopropane) dihydrochloride was obtained from Interchim $^{\circledR}$. Total antioxidant capacity was performed on a spectrofluorometric analyser (SFM 25 Kontron $^{\circledR}$ ) 


\section{Statistical analysis}

All continuous data were expressed as mean \pm SE. At the onset, the parametric data were analysed by analysis of variance (ANOVA). The time-related changes of quantitative data of each septic group (longitudinal, repeated measures) were analysed with Generalised Estimating Equations (GEEs) to account for the correlation between observations in generalised linear regression models [14]. A multivariate linear regression was used to evaluate correlation between TAC and individual antioxidants (forward step by step). Because the data for bilirubin were not normally distributed, a natural logarithmic transformation was performed before analysis for all serum bilirubin measures, so that the assumption of normal distribution would be closer to reality being met. The Fischer's exact test was used to compare mortality and sex ratio between the two septic groups (severe sepsis versus septic shock). The Mann-Whitney test was performed to compare the intake of vitamins between the two septic groups. No interim analysis was performed. A p value $<0.05$ was considered statistically significant. 


\section{RESULTS}

Fifty-six patients (19 severe sepsis and 37 septic shock) were consecutively enrolled during the course of the study, and were compared to six healthy volunteers. The demographic and clinical data for these subjects are shown in Table I.

The healthy volunteers were younger than the septic patients, but there was no difference between the two septic groups in terms of age or sex ratio. The SAPS II score and SOFA score (at the onset, at the peak and at any time of this study) were significantly higher in the septic shock group. The mortality rate was significantly lower in the severe sepsis group compared to septic shock group ( $0 \%$ versus $62 \%$, $\mathrm{p}<0.01)$. The diagnoses presented and the mean enteral intakes of vitamins are developed in Table I. No difference was found between the two septic groups in terms of vitamin $\mathrm{A}, \mathrm{C}$ or $\mathrm{E}$ intake (data for healthy volunteers were not recorded).

Values at the onset (Table II):

TAC levels and main antioxidants concentrations at the onset are presented in Table II.

At the onset, all three groups were similar in terms of TAC levels: healthy volunteers $=2.18 \pm 0.04 ;$ severe sepsis $=2.03 \pm 0.07 ;$ septic shock $=2.09 \pm 0.09$. Protein and albumin concentrations were depressed in both septic groups (significantly below those in the healthy subjects and normal values), but 
particularly so in patients with shock (concentrations in this group were significantly lower than those in the severe sepsis group).

There was no significant difference in uric acid concentrations for the three groups at the onset, and all were in the normal range.

Hyperbilirubinemia was noted in the septic shock group, and the difference with the other two groups reached statistical significance.

For each vitamin studied, plasma concentrations of the two septic populations were statistically lower than the levels of the healthy group. When vitamin E, expressed in term of lipid ratio, was kept in the normal range, vitamins $\mathrm{A}$ and $\mathrm{C}$ were below it. However, no difference was found between the two septic groups in terms of vitamin $\mathrm{A}, \mathrm{C}$ or $\mathrm{E}$ concentration.

\section{Changes during the course of the illness:}

Time course evaluation of total antioxidant capacity and antioxidants was only done for the two septic populations, as only one blood sample was taken from the healthy volunteers. In each septic group, some patients did not complete the 10 day follow-up (in-hospital death and discharge from the ICU were the main reasons). The number of patients at each follow-up time point is shown in figure 1.

Changes in TAC levels during the course of the illness:

There was no difference between the severe sepsis and septic shock group with regard to the profile of changes in mean TAC values: TAC values statistically 
declined over time $(\mathrm{p}=0.001)$ and there was no difference between the two septic populations at any time (figure 1).

Evolution of the main antioxidant levels during the course of the illness:

Uric acid concentrations showed a significant decrease over time, but the two septic groups were comparable at every time and in the normal range.

Mean total protein levels did not change over time. The severe septic group expressed higher protein values than the other group. Albumin concentrations in the severe sepsis group were higher than in the septic shock group, but a significant decrease was observed in the two groups.

Patients with septic shock maintained higher values of bilirubin during the course of the illness than severe sepsis patients (figure 2). There was no statistical evolution of bilirubin concentration over time.

Concentrations of the two lipid-soluble vitamins A and E evolved in the same way: no difference was found between the two groups at any time, and a significant increase was seen in these two vitamin concentrations over time (figure 3). For water-soluble vitamin C, the severe sepsis and septic shock curves were superimposable, and the initial deficiency worsened (figure 4).

Correlation between TAC and individual antioxidants (multivariate analysis):

TAC was statistically linked to uric acid (Correlation Coefficient $(\mathrm{cc})=0.0001, \mathrm{p}$ $<0.001)$; proteins $(\mathrm{cc}=0.013, \mathrm{p}<0.001)$; bilirubin $(\mathrm{cc}=0.02, \mathrm{p}<0.001)$ and albumin $(\mathrm{cc}=0.013, \mathrm{p}<0.02)$. No correlation was found between TAC and any vitamin, nor with the severity indexes (SAPS II and SOFA score). 


\section{DISCUSSION}

The present study found no difference in terms of total antioxidant capacity between the three groups at the onset (healthy volunteers and septic patients whatever the severity of the infection). The time-course survey showed a decrease in the TAC of septic patients but no difference between the two septic groups was seen at any time. This result does not corroborate time changes previously described: Pascual and Tsai found a higher antioxidant capacity in the more severely infected subgroups (septic shock and non-survivors respectively) while Cowley found opposite results (lower values in the more severe group) [11, 12, $15]$.

The methodologies available for the determination of total antioxidant capacity differ, in particular, in the source of free radicals. Plasma antioxidants may react to a different degree with a given source of free radicals, therefore, the different results obtained in these studies may depend on the method used for evaluation. Another explanation can be found in the discrepancies between the populations: our study compared septic patients where others compared septic and inflammatory populations (i.e.: burns, pancreatitis, immune disorders...), one study excluded patients with hyperbilirubinemia, a major antioxidant involved in TAC [15].

Multivariate analysis confirmed the link between TAC and several antioxidants: proteins, albumin, uric acid and bilirubin. These main antioxidants have already been linked to TAC [9]. Plasmatic protein and albumin concentrations were 
increasingly depressed during the course of sepsis, and the more severe the infection, the lower the values. Hypoalbuminemia has been noted in inflammatory and septic states with several pathophysiological mechanisms involved: reduction in albumin synthesis, hypercatabolism, which leads to a dramatic reduction in its half-life, hemodilution and abnormal capillary permeability, which raises albumin concentration in the interstitial fluid. Hyperbilirubinemia, seen from the onset in the septic shock group, may maintain a normal level of antioxidant capacity in these patients with low protein and albumin concentrations. Bilirubin is a powerful antioxidant: at physiologic oxygen tension, bilirubin is more effective than $\alpha$-tocopherol protector against lipid peroxidation [16]. Abnormal liver function commonly accompanies critical illness, and the major biochemical abnormality is conjugated hyperbilirubinemia. Different studies have linked hyperbilirubinemia to mortality, which corroborates our results where jaundice was seen in the more severe group $[17,18]$.

Because TAC is a composite tool, the interpretation of its variations is difficult. For example, the effects of two antioxidants on TAC are not equivalent to their cumulative properties, which offers proof of synergistic or antagonist involved interactions. Moreover, TAC levels encompass the effect of some unknown antioxidants, which have previously been involved in the decrease of redox status [15]. In our septic population, where a general decrease in individual antioxidants was seen, TAC did not differ from healthy volunteers at the onset. Also, opposite variations in other antioxidants must exist. In other antioxidants we include known antioxidants which have not been measured in this study (e.g.: superoxide 
dismutases, glutathione peroxidases ...), unidentified molecules and known substances with unsuspected antioxidant properties (e.g.: recent studies have revealed the powerful antioxidant properties of fibrinogen) [19].

Septic states are ongoing pathological processes, and the intravascular oxidantantioxidant equilibrium may respond in a timely and dynamic fashion. The relationship between the production of free radicals and the quantity of antioxidant have been demonstrated in the myocardium under different circumstances (inflammation, ischemia-reperfusion) : heart tissue has been shown to increase its antioxidant production in a pro-oxidant surrounding [20]. These fundamental characteristics may be present in our septic plasmas and can explain similar TAC levels measured in the two septic groups during the course of the illness.

This study has demonstrated that patients with acute infection have markedly decreased plasma levels of total vitamin $\mathrm{C}$, compared to normal controls, which agrees with previous fundamental or clinical studies [5, 21, 22]. Micronutrients play an important role in the defence against ROS as antioxidants or scavengers. Vitamin $\mathrm{C}$ and $\mathrm{E}$ are very important molecules involved in the first line defence in septic conditions, which generate high quantities of ROS. There is a co-operative interaction between vitamin $\mathrm{C}$ and $\mathrm{E}$ in suppressing lipid peroxidation, the mixture of these two antioxidants is much more effective than the sum of both vitamins alone [23]. In addition, vitamin $C$ regenerates $\alpha$-tocopherol from the vitamin E radical, when vitamin E acts as the primary antioxidant [24]. This point 
may be crucial in maintaining vitamin $\mathrm{E}$ in the normal range, as seen in this study and several other investigations [25, 26].

Previous studies have shown that plasma levels of vitamin C can drop very rapidly during sepsis where infused ascorbate is rapidly consumed [5] or after an ischemia-reperfusion sequence where dehydroascorbate (DHA) decomposes with a half-life of a few minutes [27]. Also, rapid and persistent oxidation, associated with insufficient intakes, probably plays a large role in our findings. In the absence of endogenous production (lack of active human gulonolactone oxidase), ascorbic acid requires efficient recycling from its oxidised forms to avoid irreversible loss [28]. DHA, the oxidised product of ascorbate, can be reduced by non-enzymatic or enzymatic reactions $[29,30]$. In normal conditions, the cellular redox state enables the majority of the oxidised forms of ascorbate to be reduced by these reactions. However, in prolonged oxidative stress, ascorbate consumption and DHA accumulation can be observed in vivo [30, 31]. Little is known about this recycling in septic conditions, and its impairment may reduce the vitamin $\mathrm{C}$ reserves of whole blood, as observed in this study. However, changes in plasma ascorbate levels do not necessarily mean deficiency: they may reflect redistribution from the plasma to cells, which can favourably influence intracellular redox status [32]. The overall effect, however, is that plasma vitamin $\mathrm{C}$ is depleted and thus unavailable to act as an antioxidant.

In conclusion, TAC was unaffected at the onset of the infection, whatever the severity of the infection, notwithstanding a deficiency in the majority of measured 
individual antioxidants. Thereafter, we found a decrease in TAC during the time course of the illness in the two septic groups. The above-mentioned inability of TAC to distinguish between severe sepsis and septic shock makes it unlikely to be a particularly useful outcome measure. 


\section{REFERENCES}

1 American College of Chest Physicians/Society of Critical Care Medicine Consensus Conference. Definitions for sepsis and organ failure and guidelines for the use of innovative therapies in sepsis. Crit. Care Med. (1992) 20, 864-874

2 Angus D. C., Linde-Zwirble W. T., Lidicker J., Clermont G., Carcillo J., Pinsky M. R. Epidemiology of severe sepsis in the United States : Analysis of incidence, outcome, and associated costs of care. Crit. Care Med. (2001) 29, $1303-1310$

3 Alenzo de Vega J. M., Diaz J., Serrano E., Carbonell L.F. Plasma redox status relates to severity in critically ill patients. Crit. Care Med. (2000) 28, 18121814

4 Alenzo de Vega J.M., Diaz J., Serrano E., Carbonell L.F. Oxidative stress in critically ill patients with systemic inflammatory response syndrome. Crit. Care Med. (2002) 30, 1782-1786

5 Galley H.F., Davies M.J., Webster N.R. Ascorbyl radical formation in patients with sepsis : Effect of ascorbate loading. Free Radic. Biol. Med. (1996) 20, $139-143$

6 Kunsch C., Medford R.M. Oxidative stress as a regulator of gene expression in the vasculature. Circ. Res. (1999) 85, 753-766

7 Laight D.W., Carrier M.J., Änggard E.E. Antioxidants, diabetes and endothelial dysfunction. Cardiovasc. Res. (2000) 47, 457-464 
8 Schrammel A., Koesling D., Schmidt K., Mayer B. Inhibition of purified soluble guanylyl cyclase by L-ascorbic acid. Cardiovasc. Res. (2000) 47, 602-608 9 Ghiselli A., Serafini M., Natella F., Scaccini C. Total antioxidant capacity as a tool to assess redox status: critical view and experimental data. Free Radic. Biol. Med. (2000) 29, 1106-1114

10 Cao G., Allessio H.M., Cutler R.G. Oxygen-radical absorbance capacity assay for antioxidants. Free Radic. Biol. Med. (1993) 14, 303-311

11 Pascual C., Karzai W., Meier-Hellmann A., Oberhoffer M., Horn A., Bredle D., Reinhart K. Total plasma antioxidant capacity is not always decreased in sepsis. Crit. Care Med. (1998) 26, 705-709

12 Cowley H.C., Bacon P.J., Goode H.F., Webster N.R., Jones J.G., Menon D.K. Plasma antioxidant potential in severe sepsis : comparison of survivors and nonsurvivors. Crit. Care Med. (1996) 24, 1179-1183

13 Vincent J.L., Moreno R., Takala J., Willatts S., De Mendonca A., Bruining H., Reinhart C.K., Suter P.M., Thijs L.G. The SOFA (Sepsis-related Organ Failure Assessment) score to describe organ dysfunction/failure. On behalf of the Working Group on Sepsis-Related Problems of the European Society of Intensive Care Medicine. Int. Care Med. (1996) 22, 707-710

14 Horton N. J., Lipsitz S.R. Review of software to fit Generalized Estimating Equation regression models. Am. Stat. (1999) 53, 160-169

15 Tsai K., Tai-Ger H., Chi-Woon K., Kuan-Chia L., Fung-Jou L. Is the peroxyl-radical scavenging capacity of plasma protective in systemic inflammatory disorders in humans ? Free Radic. Biol. Med. (2000) 28, 926-933 
16 Baranano D.E., Rao M., Ferris C.D., Snyder S.H. Biliverdin reductase : a major physiologic cytoprotectant. Proc. Natl. Acad. Sci. USA. (2002) 10, 1609316098

17 Hawker F. Liver dysfunction in critical illness. Anaesth. Intensive Care 1991 19(2), 165-181

18 Funada H., Matsuda T., Okada Y. Jaundice associated with pseudomonas aeruginosa bacteremia complicating acute leukemia. Intern. Med. (1995) 34(2), $100-103$

19 Kaplan I.V., Attaelmannan M., Levinson S.S. Fibrinogen is an antioxidant that protects beta-lipoproteins at physiological concentrations in a cell free system. Atherosclerosis (2001) 158(2), 455-463

20 Mcdonough K.H. The role of alcohol in the antioxidant balance in heart. Front. Biosci. (1999) 4, D601-606

21 Rojas C., Cadenas S., Herrero A., Méndez J., Barja G. Endotoxin depletes ascorbate in the guinea pig heart. Protective effects of vitamins $\mathrm{C}$ and $\mathrm{E}$ against oxidative stress. Life Sci. (1996) 59, 649-657

22 Chorah C., Downing C., Piripitsi A., Gallivan L., Al-Hazaa A.H., Sanderson M.J., Bodenham A. Total vitamin C, ascorbic acid and dehydroascorbic acid concentrations in plasma of critical ill patients. Am. J. Clin. Nutr. (1996) 63, 760-765

23 Leung H.W., Vang M.J., Mavis R.D. The co-operative interaction between vitamin $\mathrm{E}$ and vitamin $\mathrm{C}$ in suppression of peroxidation of membrane phospholipids. Biochim. Biophys. Acta (1981) 664, 266-272 
24 Liebler D.C., Kaysen K.C., Kennedy T.A. Redox cycles of vitamin E: hydrolysis and ascorbic acid dependent reduction of 8a-(alkyldioxy)tocopherones. Biochemistry (1989) 28, 9772-9777

25 Richard C., Lemonnier F., Thibault M., Couturier M., Auzepy P. Vitamin E deficiency and lipoperoxidation during adult respiratory distress syndrome. Crit. Care Med. (1990) 18, 4-9

26 Bulger E.M., Maier R.V. An argument for Vitamin E supplementation in the management of systemic inflammatory response syndrome. (2003) Shock 19, 99-103

27 Ozmen D., Boydak B., Mutaf I., Zoghi M., Kumanlioglu K., Guner I., Bayindir $\mathrm{O}$. The state of lipid peroxidation and antioxidants following thrombolytic therapy with rt-PA and streptokinase in acute myocardial infarction. Jpn. Heart J. (1999) 40(3), 267-273

28 Challem J.J., Taylor E.W. Retroviruses, ascorbate and mutations in the evolution of Homosapiens. Free Radic. Biol. Med. (1998) 25, 130-132

29 Mendiratta S., Qu Z.C., May J.M. Erythrocyte ascorbate recycling: antioxidant effects in blood. Free Radic. Biol. Med. (1998) 24,: 789-797

30 Bànhegyl G., Braun L., Csala M., Puskas F., Mandl J. Ascorbate metabolism and its regulation in animals. Free Radic. Biol. Med. (1997) 23, 793 803

31 Bode A.M., Yavarow C.R., Fry D.A., Vargas T. Enzymatic basis for altered ascorbic acid and dehydroascorbic acid levels in diabetes. Biochem. Biophys. Res. Commun. (1993) 191, 1347-1353 
32 Wu F., Wilson J.X., Tyml K. Ascorbate protects against impaired arteriolar constriction in sepsis by inhibiting inducible nitric oxide synthase expression. Free Radic. Biol. Med. (2004) 37, 1282-1289

33 Kalil A.C., Sevransky J.E., Myers D.E., Esposito C., Vandivier R.W., Eichacker P., Susla G. M, Solomon S.B., Csako G., Costello R., Sittler K.J., Banks S., Natanson C., Danner R.L. Preclinical trial of L-arginine monotherapy alone or with N-acetylcysteine in septic shock. Crit Care Med. (2006) 34, 27192728 


\section{Figure Legends:}

Figure 1: Evolution of plasma antioxidant capacity during the 10-day follow-up. Data are shown as means \pm SE (errors bars). Numbers at bottom represent number of patients each day, in the two septic groups

Figure 2: Evolution of bilirubin concentrations during the 10-day follow-up. Data are shown as means $\pm \mathrm{SE}$ (errors bars). X-axis represents time (days after the onset of infection).

Figure 3: Evolution of plasma vitamin E / lipid ratio during the 10-day follow-up. Data are shown as means $\pm \mathrm{SE}$ (errors bars). $\mathrm{X}$-axis represents time (days after the onset of infection).

Figure 4: Evolution of vitamin C concentrations during the 10-day follow-up.

Data are shown as means \pm SE (errors bars). X-axis represents time (days after the onset of infection). 
Figure 1

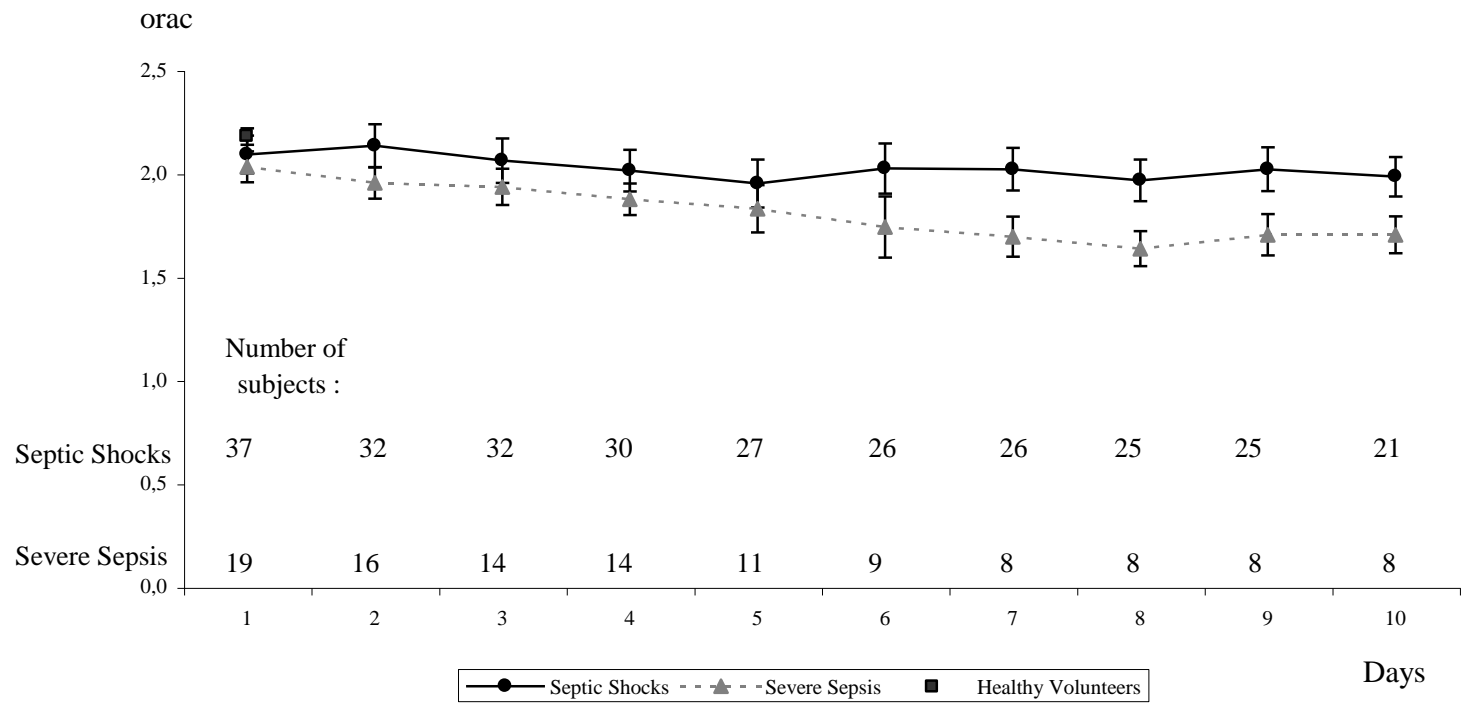


Figure 2:

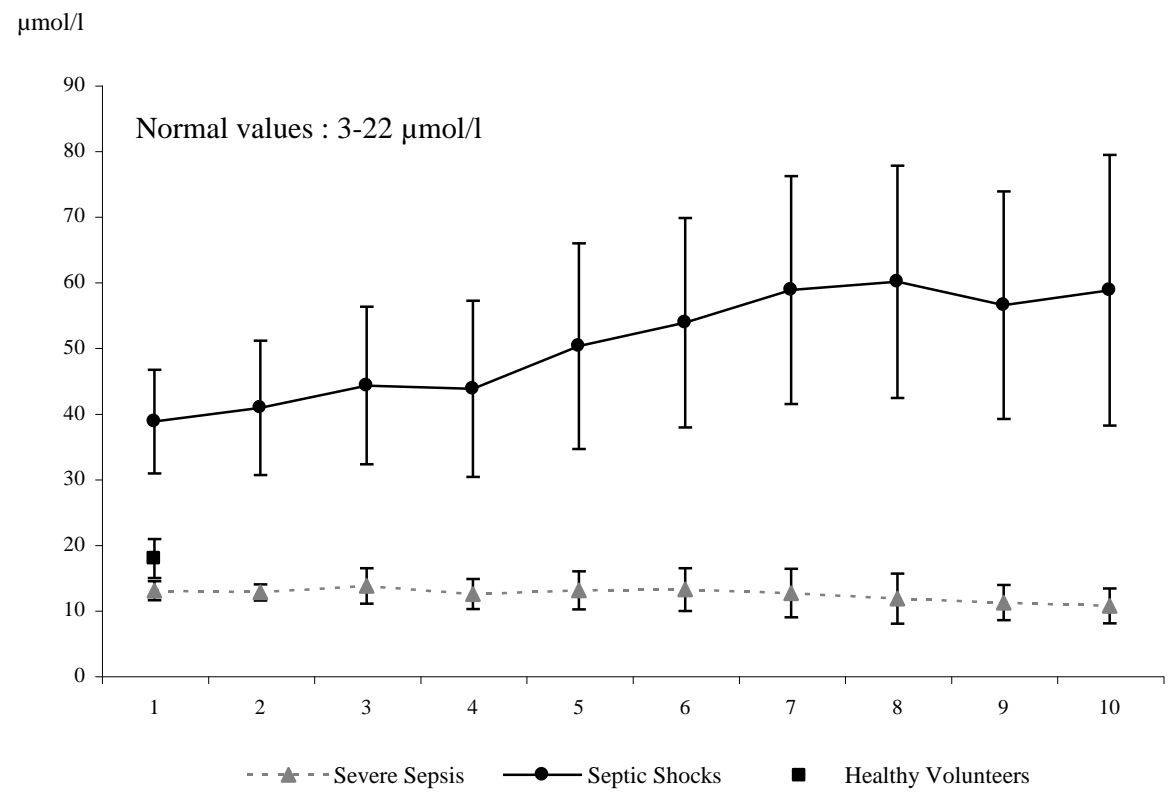


Figure 3:

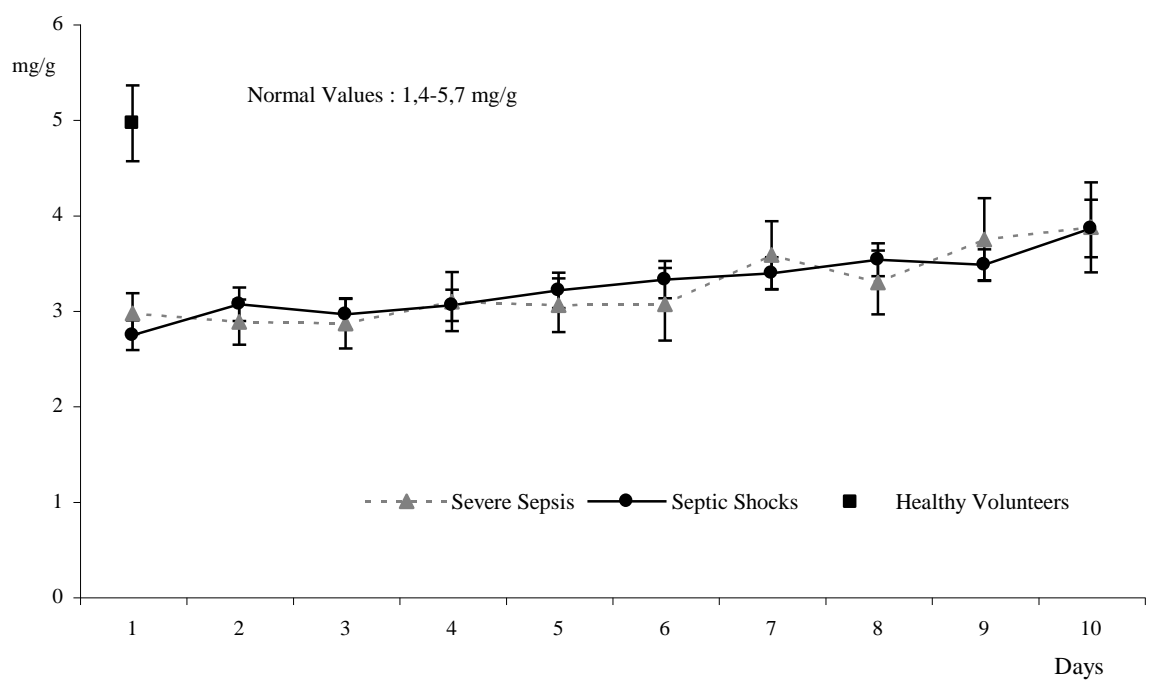


Table I: Demographic, clinical data and site of infection of the study subjects

\section{Healthy subjects Severe sepsis}

Number

Age

Female / Male

SAPS II

SOFA score at day 1

Peak SOFA score

Mortality rate

Site of infection (n)

Respiratory

Genitourinary

Abdominal

Wound / Soft tissue

Central nervous system

Endocarditis
6

$44 \pm 3$

$2 / 4$

$42 \pm 4.5$

$4.1 \pm 2.7$

$4.47 \pm 0.66$

$0 \%$

8

3

2

2

3

1
Septic shock

37

$68 \pm 2.6^{\#}$

$12 / 25$

$71 \pm 3.4^{\S}$

$12.4 \pm 2.7^{\S}$

$14.5 \pm 0.63^{\S}$

$62 \% §$

Mean vitamin intake

Vitamin A

$694 \pm 930$

$470 \pm 60$

Vitamin E

$13.7 \pm 1.9$

$9.7 \pm 1.2$

Vitamin C

$56.5 \pm 7.6$

$39.1 \pm 4.9$

Data are expressed as mean \pm SE. SAPS II $=$ Simplified Acute Physiology Score;

SOFA score $=$ Sepsis-related Organ Failure Assessment score. ${ }^{*} \mathrm{p}<0.05$

compared with healthy subjects, ${ }^{\S} \mathrm{p}<0.05$ compared with severe sepsis. 
Table II: Total antioxidant capacity and main antioxidant concentrations at the onset.

\section{Normal values Healthy subjects $\quad$ Severe sepsis $\quad$ Septic shock}

$\begin{array}{lcccc}\text { TAC } & & 2.18 \pm 0.04 & 2.03 \pm 0.07 & 2.09 \pm 0.09 \\ \text { Proteins } & 63-82 \mathrm{~g} / \mathrm{l} & 76.2 \pm 1.6 & 59.6 \pm 2.1^{\#} & 50.6 \pm 2.0^{\# \S} \\ \text { Albumin } & 35-50 \mathrm{~g} / \mathrm{l} & 43.5 \pm 1.3 & 26.3 \pm 1.3^{\#} & 21.4 \pm 1^{\# \S} \\ \text { Uric acid } & 145-510 \mu \mathrm{mol} / \mathrm{l} & 293 \pm 51 & 376 \pm 39 & 443 \pm 43 \\ \text { Bilirubin } & 3-22 \mu \mathrm{mol} / 1 & 17.8 \pm 3.0 & 12.9 \pm 1.4 & 38.7 \pm 7.9^{\S} \\ \text { Vitamin A } & 0.4-1 \mathrm{mg} / 1 & 0.6 \pm 0.1 & 0.24 \pm 0.04^{\#} & 0.2 \pm 0.02^{\#} \\ \text { Vitamin C } & 45-90 \mu \mathrm{mol} / \mathrm{l} & 48.2 \pm 6.0 & 13.9 \pm 3.3^{\#} & 13.9 \pm 3.1^{\#} \\ \text { Vitamin E / lipid } & 1.4-5.7 \mathrm{mg} / \mathrm{g} & 4.96 \pm 0.4 & 3.0 \pm 0.2^{\#} & 2.7 \pm 0.2^{\#} \\ & & & & \end{array}$

Data are expressed as mean $\pm \mathrm{SE} . \mathrm{TAC}=$ Total Antioxidant Capacity. ${ }^{\#} \mathrm{p}<0.05$ compared with healthy subjects, ${ }^{\S} \mathrm{p}<0.05$ compared with severe sepsis. 